Research projects. As a result of recommendations made by the Committee at previous meetings, Uneseo has given grants for research on the following subjects: the geographical potentialities of coastal deserts; a survey of wind energy and of energy requirements in a typical arid area (Somaliland); the flow of underground water in calcareous mountains ; the sulphate- and nitrate-rich soils of Algeria; changes in climate during the Quaternary Period in Israel, as evidenced by pollen analysis ; the role of dew in plant growth in arid regions ; plant ecological studies in French North Africa; the role of vertebrates in spreading desert conditions in India; and the physiology of the camel. At the meeting in Paris, reports on these investigations were received by the Committee, and grants were recommended for the development and testing of apparatus for the measurement of dew and for the study of plant distribution and ecology in the Rajistan desert in India.

Future meeting. The Committee will hold its next session in New Delhi during October this year in conjunction with the symposium on wind and solar energy that has been arranged at the invitation, and with the help, of the Government of India.

\section{CHEMISTRY AND PHYSICS OF SYNTHETIC FIBRES}

$\triangle$ LTHOUGH the subject of 'man-made' fibres is $A$ well to the fore in the world of polymer technology and names of new fibres such as 'Terylene' and 'Orlon' are beginning to compete in the housewife's mind with nylon, major discussions in Britain on chemical aspects of this topic have been few. The three-day symposium held during March 24-26 by the Plasties and Polymer Group of the Society of Chemical Industry on the subject of "The Chemistry and Physics of Synthetic Fibres", at the Institution of Electrical Engineers, Savoy Place, London, was therefore timely. More than three hundred participants, including a number from overseas, attended, and some interesting papers were read and discussed. During the first session, Mr. J. R. Whinfield ('Terylene Council, Imperial Chemical Industries, Ltd.), chairman of the Group, presided.

Dr. R. Hill (Terylene Council, Imperial Chemical Industries, Ltd.), in an introductory paper on "Chemical Aspects of Jibres", discussed the structural features in polymers which have led to the mechanical behaviour characterizing rubbers, plastics and fibres; for the development of fibre properties a macromolecule needs to possess a regular, crystallizable structure and high interchain forces. In materials such as polyamides, polyurethanes and polyesters, these features are present, but fibre properties can be seriously affected if any branching or cross-linking occurs during condensation owing to the presence of impurities. In the vinyl polymer field, Dr. Hill referred to grafting, a new method by which the properties of a given polymer can be modified. It seems unlikely, partly for economic reasons, that any completely new fibre-forming polymers will be commercialized in the near future, but possible develop. ments in such materials as polyvinylidene cyanide and polymers obtained by ring-opening of oxacyclobutane derivatives and $\mathrm{N}$-carboxyamino-acid anhydrides were mentioned.
Among the new materials which have aroused interest in recent years are the polyaminotriazoles, which may be obtained by the reaction of dibasic acids with rather more than two moles of hydrazine; the recurring polar linkage in these polymers is a 4 -amino$1: 2: 4$-triazole ring. Mr. J. W. Fisher (British Celanese, Ltd.) gave an account of the chemistry and use of "Polyaminotriazoles as Fibre-forming Materials". A typical polyaminotriazole, that based on sebacic acid, has a melting point of $256^{\circ} \mathrm{C}$. and can be melt-spun and cold-drawn to give yarns with mochanical properties generally similar to those of nylon or 'Terylene' and which can readily be dyed with dispersed acetate and wool colours. A structure of the polymer, as shown by X-ray examination, was proposed, involving a planar chain in which the octamethylene segments zig-zag at an angle of $20^{\circ}$ on either side of the general fibre axis, and a resonant triazole ring; hydrogen-bonding between exocyclic amino-groups and nitrogen atoms in another ring is thought to be responsible for the high melting point of the polymer.

Turning to a subject related to the production of synthetic fibres from a natural material, Dr. W. E. F. Naismith (Nobel Division, Imperial Chemical Industries, Ltd.) discussed the "Chemical Denaturation of Groundnut Protein and Fibre-Formation". The globular proteins of groundnut must first be converted to an unfolded configuration (denaturation) before they can be spun: the denaturation by urea, guanidine salts and a series of organic bases has been investigated by measurement of the rise in viscosity increments of the solutions, and interpreted in terms of an increase in asymmetry of the protein molecules, using Simha's equation to calculate axial ratios. A definite relationship has been found between the ability of a base to cause rise in viscosity increment, and its ability to give spinnable solutions.

Few fundamental studies have been published of the industrially well-established processes for preparing polyamides from compounds containing carboxylic acid and amino-groups or by opening lactam rings. Dr. A. B. Meggy (University of Leeds) outlined a new thermodynamic method of attack in a paper on the "Free Energy of Formation of the Amide Bond in Polyamides". Equations were deduced in the case of the equilibrium between carboxyl, amino and amide groups and water molecules, relating the equilibrium constant $k^{\prime}$, the number-average chain length and the partial pressure of water. The effect of the presence of a cyclic monomer in amount determined by a second equilibrium constant $k_{2}$ was discussed, in cases where 5- to 8-membered rings might be formed. From somewhat limited data on the variation of $k_{2}$ with temperature $T$ for e-caprolactam, the heat of formation $\Delta H$, entropy $\Delta S$ and free energy $\Delta F$ of the polyamide bond in polyaminocaproic acid have been calculated; the value of $\Delta H$ obtained agrees well with the experimental value. In the subsequent discussion, Dr. J. Saunders referred to other data on $k_{2}$ versus $T$ which give a $\Delta H$ value according to Dr. Meggy's method which is considerably too high.

During the second session, Prof. J. B. Speakman (University of Leeds) assumed the chair. Dr. I. B. Morgan (Dyestuffs Division, Imperial Chemical Industries, Ltd.) discussed "Crystallization Phenomena in Fibre-Forming Polymers", his paper being illustrated by an excellent film showing the crystallization of polyethylene terephthalate from its melt, 
in spherulitic structures. Dr. Morgan's main thesis was that, after nucleation, preferential crystal growth takes place along the direction of the polymer chains rather than by sideways accretion, and that, during growth, coiling occurs with the formation of long helical polymer crystals. The ultimate result is the formation of coiled families of fibrillar crystals, which explains a good many of the physical characteristies of erystalline polymers, particularly the fact that in the spherulites the chains are known to be arranged tangentially. This paper provoked a great deal of controversy. Mr. C. W. Bunn was very doubtful if the physical evidence, particularly from electron microscopy, really justifies the theory of helical coiling, for which, in a perfectly symmetrical polymer, thore is no apparent reason. Dr. I. R. G. Treloar also failed to see how helical structures of the size required by Dr. Morgan's theory could be formed.

Dr. G. Meacock (British Nylon Spinners, Ltd.) gave an account of the "Production of Fibres from $6,6-, 6,10$ - and 6-polyamides"; although the 6,6polymer is somewhat less thermally stable than the other two, it has a higher melting point and greater strength at high temperatures. While all the polymers can be spun by similar methods to give similar fibres, the 6-polymer has the disadvantage of evolving its monomer during spinning, which complicates the process.

Dr. J. A. Chapman and Dr. J. W. Menter (University of Cambridge) then gave a brief account of some work they have been doing on the examination of fibre surfaces by reflexion electron microscopy. The micrographs exhibited show this to be a powerful method for observing the effect of frictional wear.

Cold-drawing and, in particular, 'necking' in fibres has until very recently been something of a mystery, which the authors of the next paper, "The Drawing of Terylene", by I. Marshall and A. B. Thompson ('Terylene Council, Imperial Chemical Industries, Ltd.), have done much to clear up. Their paper was also illustrated by a fascinating film of the experimental drawing apparatus in action. By a consideration of load extension curves at various temperatures, the position of the draw point can be predicted; but complications arise owing to the crystallization of 'Terylene' during the process, and to necking. When necking takes place during the passage of the filament over a heated plate, the draw point only remains fixed relative to the plate over a fairly narrow range of draw ratios and temperatures ; outside these limits, the draw point retreats to the feed roll or advances to the draw roll. The theoretical interpretation of these facts was given. During the discussion, Dr. H. T. Hookway commented on the relationship between second-order transition temperatures and temperatures at which necking could occur. Dr. D. V. N. Hardy mentioned a number of phenomena associated with the heat generated at the neck.

R. A. Horsley and J. Jack (B.X. Plastics, Ltd.) turned to the subject of vinylidene chloride copoly. mers, and gave details of the "Extrusion Properties of Saran Monofilaments". They described a commercial machine for extruding and stretching saran, and discussed various points of design. The effect on tensile strength, loop strength and elongation of variables such as distance between die and quench bath, stretch ratio, quench bath temperature and stretching temperature were given.
The symposium chairman on the third day was Mr. J. Wilson, director of the British Rayon Research Association. The first speaker was Dr. A. R. Urquhart (Shírley Institute, Manchester), who read a paper on "Cellulose Acetate as a Raw Material for IRayon Production". After giving a historical account of the development of 'secondary' acetate rayon, Dr. Urquhart went on to compare some of the properties of acetate with those of nylon, 'Orlon' and other synthetic fibres, with particular reference to subjective qualities such as drape and compliance; 'Terylene' and 'Orlon' staple fibres approach acetate and wool in these respects. The water absorption of acetate is lower than that of viscose, but higher than that of nylon, 'Terylene' or 'Orlon', which gives the latter fibres an advantage in rate of drying after washing; however, considerations of hygiene and comfort require that a fabric should be able to absorb a considerable amount of moisture, and rate of drying is really only a secondary consideration. A vigorous discussion was held on this paper, contributions being made by Dr. Corbiere, Dr. E. Kornreich, Mr. J. G. P. Baker and Dr. R. M. Lodge, and it was obvious that views on the comfort to the wearer of the various synthetic fabrics were somewhat divided; it was pointed out that the fabric construction is important, and that one outstanding property might for some purposes outweigh many other considerations.

Dr. T. H. Morton (Courtaulds, Ltd.), in his paper on "Textile Properties of Synthetic Fibres", also referred to the importance of those properties of a fabric which for assessment require a certain amount of subjective judgment, and in a detailed discussion graded various old and new fibres in a number of classes. All the established fibres have some good points and some properties which can be improved. It is not possible to say that one fibre is better than another, since they all have particular fields in which they are specially useful. Dr. Morton suggested that it will be a very long time before the 'perfect' fibre, having ideal properties in all respects, is produced. Nevertheless, the textiles obtainable using the present materials, alone or blended, cover a very wide range of properties. This paper also was followed by considerable discussion. In regard to dyeing hydrophobic fibres, the difference between what is possiblo and what is regarded as practical to the dyer was pointed out. The cohesion of cellulose fibres is dependent on secondary valency forces, some details of which were given by Dr. J. Mann and Dr. H. J. Marrinan (British Rayon Research Association) in their paper on "Hydrogen Bonding in the Crystalline Regions of Cellulose". The study of infra-red absorption changes on interaction of cellulose and heavy water enables stretching of the hydroxyl groups in the crystalline and amorphous regions to be observed independently. All the hydroxyl groups in the crystalline regions of regenerated and bacterial cellulose are found to be hydrogen-bonded, which rules out certain previously proposed crystal structures. Hydrogen bonds of types $\mathrm{O}-\mathrm{H}$.... O and also $\mathrm{H} \ldots \mathrm{O}-\mathrm{H} \ldots \mathrm{O}$ are present in regenerated cellulose. Commenting on this paper, Dr. L. Valentine referred to regions in cellulose acetates and trimethyl cellulose found to be inaccessible to water vapour; such regions are presumably crystalline.

The static electrification of textile fibres is well known, and often troublesome. Prof. E. Darmois (Paris), in a résumé of work on this subject, pointed 
out that wool and silk become positively charged on rubbing, but polyvinyl chloride fibres ('Rhovyl') become negatively charged. A blend of 25 per cent polyvinyl chloride fibre and 75 per cent wool takes on no charge at all. Prof. Darmois outlined his theory of these effects.

The chairman, Mr. J. Wilson, summed up the symposium. He observed that a wide range of topics had been covered, some of which are individually worth a complete meeting for themselves, having regard to the large amount of work which is going on and to the vigorous discussions which were held, particularly on the subjects of crystallinity and the relationship between fibre and fabric properties.

\section{THE WORKER IN INDUSTRY}

$\mathrm{I}^{\mathrm{N}}$

TRODUCING a joint paper presented to the annual conference of the British Institute of Management at Harrogate in 1953, K. H. F. Murrell, director of the ergonomics department of Tube Investments, Ltd., stated that the main contribution of the psychologist to industry would be in studying the effect of bad equipment design on the health and efficiency of workers on a long-term basis. This would include such factors as the posture, either seated or standing, which the equipment imposes on the worker, and which may follow either from the shape of the equipment or from the design of its controls; the actual methods by which work is done, such as the application of force in an unnatural position; and the conditions of heat or noise tnder which he has to work. Much of industry works below maximum efficiency because it has, through neglect of physiological principles, partly 'worn-out' its working force. The most important contribution of the psychologist might be summed up as attempting to answer various aspects of the question "What makes people behave as they do when confronted with a given situation and what can be done about it ?" Some of these aspects might be: What is a real incentive for people to work? Why do people resist change ? Is there such a thing as fatigue in repetitive work or is it merely monotony or boredom? What is the nature of skill in a particular task and how can it best be acquired?

To be effective the research worker must be familiar with the worker on the job and, from his own experience, Murrell gave examples to show how good theoretical research had been ineffective because it had failed to take account of the actual work situation.

A. T. Welford, director of the Nuffield Unit for Research into Problems of Ageing in the University of Cambridge, described a closely connected series of studies on some problems of speed in human performance. Men of different ages from the twenties to the seventies were set to work at a task where they had to plot positions on a grid by moving a pointer. The older men were on average substantially slower than the younger, but the slowness was not due to slowness in moving the pointer; it was rather due to more careful and meticulous placing of it.

The same results appeared in several other tasks ; an experiment was accordingly devised in which careful measurements were made of reaction times and movement times under conditions where they could be separated with certainty. A man doing a task sat in front of a panel of four lights. One of these came on and the operator had to move a lever in the corresponding direction as quickly as possible from a central point to an end stop and back again. As soon as he got back to the centre another light came on, and so on. When the results were examined it was found that the actual time moving did not increase but tended to fall with age. The time elapsing between a light appearing and the man beginning to move the lever did increase significantly. A further point with this was noticed, in that the oldest men, in their sixties, tended to fall slightly at the end stop. The older men appeared to be having difficulty in welding the out and back movements into a single whole. These experiments link with a number of other results to suggest an important general principle, namely, that it is the time taken over stationary portions of a manipulative task which are more deserving of attention. These tend to increase with certain types of fatigue.

Evidence would seem to be accumulating that it is not correct to think of a manipulative operation as consisting merely of a series of movements. It consists rather of a series of acts of perception either by the eyes or by touch or by sound which have to be translated into movement. It is the perception and translation by the central media of the brain which are the important components of the operation, and it is in terms of these that operators must be analysed for work study purposes if general results are to be obtained which apply more widely than to each individual operation studied.

Welford also said that, while relatively little interest has been shown by psychologists in training the industrial worker, there is great scope for further co-operation between experimenters and industry. One example of a study with important practical implications was the one carried out about four years ago by G. B. Gibbs, of the Medical Research Council. Gibbs studied the performances of men on a machine where the display-control relationships could be made easier or more difficult. He divided the men into two groups of equal ability and trained one, first on a relatively easy task, and then transferred them to one which was similar but in which the displaycontrol relationships were more difficult. The other group were trained on the same two tasks but in the reverse order. The results showed clearly that the second group, after being trained on the difficult task, came to the easy one and performed it much better than they would have done if they had not had the previous difficult training. With the other group Gibbs found that the previous training on one easy task made no difference to their ability to perform the more difficult one.

Dr. H. D. Darcus, of the Climatic and Working Efficiency Unit of the Medical Research Council, stated that one of the possible approaches to the study of the activity of man at his work is to find out under what conditions the man may be allowed to work at his greatest physiological efficiency. Emphasis should be placed on the output of the man rather than the effort the man has to put in to achieve that output. This is probably acceptable in most work situations because the operator is only using a small proportion of his total capacity and he can be expected to do a little bit more without suffering physical harm. The load to which a man is subjected should be kept as low as possible to give him a reserve of effort, a reserve capacity. If 